\title{
Educational Research Projects as New Form of Educational Methodology
}

Bekim Fetaji

b.fetaji@seeu.edu.mk

Majlinda Fetaji

m.fetaji@seeu.edu.mk

Alajdin Abazi

a.abazi@seeu.edu.mk

Mirlinda Ebibi

m.ebibi@ibu.edu.mk

* South East European University, Contemporary Sciences and Technologies, llindenska bb, 1200 Tetovo, Macedonia ** International Balkan University, Information Technology, Skopje, Macedonia

\section{Doi:10.5901/jesr.2015.v5n1s1p43}

\section{Abstract}

Research study has focused on investigating: could we transform today's outmoded education system to a vibrant learning ecosystem that puts learners at the center?, how technology is changing the way we teach and more importantly the impact it has on the way students learn? The study focused primarily on two objectives. Firstly on assessing and evaluating issues and deficiencies in the current state of technology enhanced education, the second objective, proposing and recommending solutions to the findings from the secondary research and answer both research questions from above. Creating personalized learning for all the learners requires a paradigm shift in current educational methodologies in practice and a deep commitment in order to guide this process tempered with wisdom and based on evidences of practical benefits. The research study is primarily trying to answer these research questions and focused on devising a set of guidelines and recommendations for designing new educational methodology based on the previous analyses. Findings and recommendations are provided.

Keywords: Educational methodologies, educational research projects, technology enhanced education, learning modeling approaches, e-learning

\section{Introduction}

Education has seen big changes, many of which have been technology-driven: social networking tools like facebook, twiter, google +, Linkedln,, the expanding role of e-learning, sophisticated learning-management systems, and new communication tools. Also major impact is realized from, open educational resources (OERs), massive open online courses (MOOCs), and the benefits and challenges of online learning.

Perhaps the most important issues concern how technology is changing the way we teach and more importantly the impact it has on the way students learn. Technology enhanced education also known as e-learning is becoming very important. There has been a greater need for learning technologists to step in and help communities benefit from technology. The role of learning technologists is essential to integrate new technologies and education.

The main research focus of the study is can we transform today's outmoded education system to a vibrant learning ecosystem that puts learners at the center and enables many right combinations of learning resources, experiences, and supports to help each child succeed? Creating personalized learning for all the learners requires a paradigm shift in current educational methodologies in practice and a deep commitment in order to guide this process tempered with wisdom and based on evidences of practical benefits. 


\section{Literature Review}

There is evidently a lack of support for instructional techniques and pedagogical learning models, as well as procedures or guidelines how, when and for what particular situation each pedagogical learning model should be supported in the software development process and its conjunction and correlation with the instructional strategies (Fetaji, 2007d).

Instructional strategy is a very important concept that needs to be addressed because the main purpose of any learning activity should be clear to the learner (Merrill et al. 1996).

Instructional design in an e-learning environment can foster the alliance between technology and education for pushing higher education to transform the academic environment. A properly executed instructional design can help faculty and academic departments develop new modes of instruction that use various technologies and teaching strategies. Instructional design represents analysis of learning needs and systematic development of instruction. Instructional design models typically specify a method in using the technology that if followed will facilitation of the transfer of knowledge, skills and learning process (Merrill et al. 1996). This learning dimension should provide the context of instruction and desirable outcome. The learning environments require high level of self-organization and metacognitive abilities from the learners engaged in the process of learning that should be captured by the instructional techniques.

There are five main instructional strategies that are currently considered: Problem Based, Project based, Inquirybased Learning, Task based and Game based learning (Helic et al 2005), (Marjanovic, 2005), (Schroeder, et al 2006), (Mitchell, 1993).

Problem based learning represents the learning that results from working with problems that needs solving. The entire learning process is set around a problem introduced and the knowledge is developed as a consequence of trying to solve the problem. Official description offered by (Mitchell, 1993) generally describe it as "an instructional strategy in which learners confront contextualized, ill structured problems and strive to find meaningful solutions and learn in the process of doing it. "In general it is an approach to learning focusing on the process of solving a problem and acquiring knowledge. The approach is also inquiry-based when learners are active in creating the problem. The learners are elevated to the position of analyst and problem-solver and have specific objectives and deadlines to meet. According to (Savery, et al 1995) there are two critical issues involved in presenting the problem. First, if the learners are to engage in authentic problem solving, then they must own the problem. A second critical issue in presenting the problem is to be certain that the data presented does not highlight critical factors in the case. Either the problem must be richly presented or presented only as a basic question. Learning should be synthesized and organized in the context of the problem.

Project-based learning (PBL) is a model that organizes learning around projects. Definitions of "project-based instruction" include features relating to the use of an authentic ("driving") question, a community of inquiry, and the use of cognitive (technology-based) tools (Krajcik, et al 1994). Project-based instruction is an authentic instructional model or strategy in which learners plan, implement, and evaluate projects that have real-world applications beyond the classroom (Harwell, 1997). Projects sometimes go off track, with teachers and students pursuing questions that are peripheral to the subject matter of interest. The solution, according to (Blumenfeld et al. 1991) is to find ways for projects to center on "learning appropriate goals. "

Inquiry-based Learning according to (Lin, et al 2006) represents an instructional strategy were involvement in learning implies processing skills and metacognitive abilities in order to seek answers to questions and issues while at the same time constructing new knowledge. Numerous inquiry-based instructional models, such as Authoring Cycle and Inquiry Cycle have been developed to support different learning activities. "Inquiry" is defined as seeking information by questioning. While questioning and searching for answers are extremely important parts of inquiry, effectively generating knowledge from this questioning and searching is greatly aided by a conceptual context for learning. According to (Helic, et al 2006) it usually begins with posing a problem or question, followed by generating and pursuing strategies for investigating, collaborating, reflecting, and justifying the solutions of the problem or answers to the question, and communicating the conclusions.

Task-based learning is an educationally sound, effective and efficient instructional strategy for learning focusing the learning activities around tasks. The term "task-based learning" according to (Nunan, 1989) originated primarily from the work done in language education. According to (Harden et al, 1996) the learning tasks play a fundamental role in determining the learning outcomes. According to (Harden et al, 1996) it has three advantages:

1. TBL is learning built round tasks is more effective than traditional didactic memory-based or purely apprenticeship-type learning;

2. TBL is learning structured round the tasks is an efficient approach to learning;

3. TBL is likely to lead to more relevant and appropriate education; 
4. TBL links theory with practice. The practical task becomes the starting point for the theory: in turn, theory informs and leads to a better understanding of the task (suits to curricula study program);

5. TBL provides an appropriate framework for planned education (curricula driven) where it makes explicit what is to be achieved and how the learner should do this (efficient learning);

6. A TBL approach is likely to result in greater relevance of curriculum content (appropriate for curricula learning).

TBL offers a focused and structured approach to learning and increases the learners' satisfaction and motivation, and at the other side is consonant with current theories of education (Harden et al, 1996). This is the reason we decided to implement a task-based model for the prototype.

Task-based learning offers action and reflection, while in contrast, rote learning is low in action and in reflection. According to (Harden et al, 1996) incidental learning, such as occurs in on-the-job learning, is rich in action but may be low in reflection. Classroom, or formal, learning is frequently high in reflection but low in action.

Game based learning or also lately refered to as digital game-based learning (Prensky, 2001), goal based scenarios and instructional games and simulations are alternatively used to describe the instructional strategy were learning activities are organized around a game or simulation. The academic community regarded game based learning as part of problem based learning using simulations and did not give much of attention in its research, and still today there are a lot of opinions in this regard (Yacci, 2004). According to (Yacci, 2004) educational games and simulations are defined as activities that have rules and constraints, a goal, and an emphasis on competition and also has the additional feature of having a primary objective of enabling a student to learn either facts, skills, attitudes, or all three. (Eklund, 2000) suggests that transfer of knowledge is aided when students actively construct explanations for events. Perhaps the biggest benefit for game -based learning is the fact that it involves students who need to learn complex skills and need to transfer these skills to real life.

However there are no clear procedures, methodologies or rules what learning modeling approach is more appropriate to use when developing e-learning solutions and especially its conjunction and correlation with the instructional strategies discussed previously.

The design and development of e-learning can not be based only in the existing practice of technology, it is necessary to understand the relation between theory and practice to ensure that the design of practice is founded on the learning theory. This concept defined by (Harmon,et al 2003) is given in the figure below:

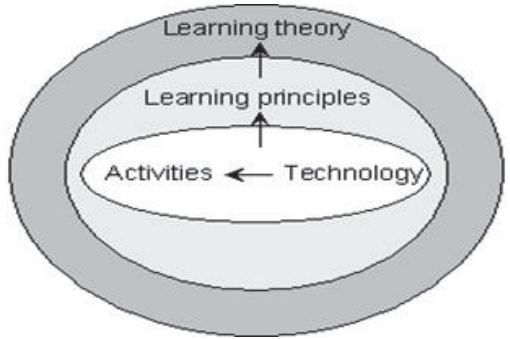

Figure 1 - Theoretically grounded evaluation of technology (Harmon,et al 2003)

E-Learning modeling approaches are very important in the process of the development of e-learning solutions as software products. Although recently in the e-learning community there is acknowledged the importance of pedagogy however there is little research on learning modeling approaches.

It describes that the different learning activities that are driven in the learning environment are supported by the elearning instructional technologies stated above. The learning principles are formed by the learning activities to be done to produce the learning outcome. The learning activities are crucial to define the features and abilities the learning environment has to support and are supported by the technology.

According to (Marjanovic, 2005) the e-learning solutions development process adopts one of the following learning modeling approaches:

1. the content-oriented,

2. the tool-oriented, or

3. the task-oriented approach 
The content-oriented approach deals with management of learning content. It is mainly concerned with supporting authoring, structuring, delivering, sharing, re-using, and querying the content (Helic, 2006). The design and authoring of e-learning content requires major input from instructional designers, graphics designers, and programmers. Normally the instructors are expected to develop the content for e-learning on their own. However content creators search for a theoretical basis to justify their designs (Eklund et al. 2003). Normally the instructors are expected to develop the content for e-learning on their own. However they are not aware of the effective methods which can be used to present their content to users. Especially the novice instructors need additional support in developing interactivity since it involves programming. Support might include collaborative tools for enriching the learning content by writing comments and annotations, tools for tracking the student progress with the content, or tools for adapting the content to the students' preferences (Helic, 2006).

Tool-oriented approach is based on using the technological infrastructure in the learning process. Learning sessions which follow this approach are organized around the use of the developed software (Helic, 2006). The developed software solution is the main vehicle into increased transfer of knowledge. This learning modeling approach provides clear support and focuses the learning process around the developed tool of instruction as medium.

Task-oriented approach deals with learning tasks or learning activities which learners need to perform in their learning sessions. Those tasks are typically structured in very simple learning sequences that the students need to pass in a sequential mode (Helic, 2006). This learning modeling approach clearly support and focuses the learning process on previously created scenarios of sequential tasks that will guide the learner activities into more efficient and higher level of knowledge transfer.

\section{Conclusions}

There are a lot of new methodologies that are considered as advanced and that are considered as the future of $\mathrm{e}$ learning. Learning object methodology, semantic web, Learning Activity Management System (LAMS) and others are considered as new trends and hot topics in e-learning. However, based on the conducted review and important synthesizes of current state of the art in the field of e-learning and e-learning solutions applied the study represents the next conclusions.

Most of the published research papers evidence that different e-learning projects are consisted of only monolithic learning systems and also many current e-learning initiatives follow the "one-size-fits-all" approach (Fetaji et al 2007). Typically, this approach is related to lack of knowledge of the learner audience or factors influencing that audience and therefore fail to provide satisfactory support for most of the learner audience. Conclusion is that we need to focus on some other issues first before we offer learners one of the above discussed monolithic systems.

Regarding the first objective 1) assessing and evaluating issues and deficiencies in the current state of e-learning projects a conclusion is that there are a lot of deficiencies. Some of the most important have been reviewed and analyzed above. The most important issue remains the one dimensional approach to e-learning and failing to recognize and acknowledge its multidimensional nature. A conclusion has been achieved that among the main reasons for the current unsatisfactory results in many e-learning initiatives and in meeting the e-learning expectancies are the above mentioned deficiencies. Therefore, the research strategy should try to address and solve the above identified issues.

Regarding the second objective, 2) Proposing and recommending solutions to the findings from the secondary research based on analyses and literature review. The conclusion is that there is a need to raise the awareness of the factors influencing e-learning in order to enhance learning and identify the nature of obstacles being faced by e-learners as well to approach e-learning recognising its multidimensional nature and trying to address several issues using a methodology that interconnects all of these issues but still addresses their multidimensional specifics.

Therefore, we believe that no new systems are needed but a series of experiments has to be conducted to see what does and does not work in a particular situation and to provide guidelines and recommendations for that situation.

Based on the findings of the research study there are too many factors and personalization that it would be wrong to view the entire process in global. The study views each particular e-learning initiative as specific in many particularities and requires special approach for each one that needs to start with assessment, measurement and evaluation of the defined e-learning indicators. The study proposes is that as starting point in any e-learning initiative to start from measuring and evaluating the factors influencing e-learning that are represented as e-learning indicators, (Fetaji et al 2007).

Therefore there is a need to raise the awareness of the factors and concepts influencing e-learning in order to enhance learning and identify the nature of obstacles being faced by e-learners through the e-learning indicators 
methodology proposed by Fetaji (2007) and undertake several experiments to see what works in particular situation and try to propose recommendations, procedures and guidelines regarding the gained insights from the experiments.

Based on the review of Learning theories and analyses of learning modeling approaches the study as new learning methodology proposes to engage learners with educational small projects that would require the leners to engage in research within each of the courses. This means that will embrace Project Based Learning which will offer learners the opportunity to be engaged in hands on study and practice the learned content through the project.

In the south East European University - SEEU, under the Instructional Support Center (ISC) (http: //www. seeu. edu. $\mathrm{mk} / \mathrm{english} / \mathrm{isc} / \mathrm{home}$. html) the faculty are encouraged to use the practical information gained from these research findings and most important tried-and true techniques form these research to improve instruction of their e-learning content. Instructional design in an e-learning environment can foster the alliance between technology and education for pushing higher education to transform the academic environment. The questions that we have opposed the tutors and students to are the next: What does this mean to me? How can I use it? Is this better than what I am doing now? Trying to answer these questions helped tutors to create e-learning content with instructional sound design that will invoke higher level of knowledge and level of learning.

Embracing instructional technology methods helped in increasing the learning process while decreasing costs at the same time. For example we have used it to provide the opportunity for students to interact with experts, even they were not located physically in the campus but were from the region. In order to realize this we have used discussion forums and video conferencing sessions in real time that did prove very efficient and were highly welcomed.

\section{References}

Barron, B. J. S. , Schwartz, D. L. , Vye, N. J. , Moore, A. , Petrosino, A. , Zech, L. , Bransford, J. D. , \& The Cognition and Technology Group at Vanderbilt. (1998). Doing withunderstanding: Lessons from research on problem- and project-based learning. The Journal of the Learning Sciences, 7, 271-311.

Blank, W. (1997). Authentic instruction. In W. E. Blank \& S. Harwell (Eds. ), Promising practices for connecting high school to the real world (pp. 15-21). Tampa, FL: University of South Florida. (ERIC Document Reproduction Service No. ED407586)

Blumenfeld, P. C. , Krajcik, J. S. , Marx, R. W. , \& Soloway, E. (1994). Lessons learned: How collaboration helped middle grade science teachers learn project-based instruction Elementary School Journal, 94, 5, 539-551.

Eklund, J. , Kay, M. , \& Lynch, H. (2003). E-learning: emerging issues and key trends. A discussion paper, Australian National Training Authority.

Fetaji, B. , \& Fetaji, M. (2007j). "E-learning indicators approach in developing e-learning software solutions", IEEE EUROCON 2007 conference, Warsaw, Poland, USA, 09-12 September 2007.

Harden, Jennifer M Laidlaw, Jean S Ker and Helen E Mitchell (1996) Task-based Learning: An educational strategy for undergraduate, postgraduate and continuing medical education, AMEE Medical Education Guide No 7, Medical Teacher (1996) 18,1 pp 7-13 and 18,2 pp 91-98

Harwell, S. (1997). Project-based learning. In W. E. Blank \& S. Harwell (Eds. ), Promising practices for connecting high school to the real world (pp. 23-28). Tampa, FL: University of South Florida. (ERIC Document Reproduction Service No. ED407586)

Helic, D. (2006): Technology-Supported Management of Collaborative Learning Processes, In International Journal of Learning and Change, Vol. 1, Issue 3, pages 285-298, 2006.

Krajcik, J. S. , Blumenfeld, P. C. , Marx, R. W. , \& Soloway, E. (1994). A collaborative model for helping middle-grade science teachers learn project-based instruction. The Elementary School Journal, 94, 483-497.

Marjanovic, O. (2005). Towards A Web-Based Handbook of Generic, Process-Oriented Learning Designs. Educational Technology \& Society, 8 (2), pp. 66-82.

Merrill, M. D. , Drake, Leston, D. , Lacy, Mark J. Pratt, \& Jean A. and the ID2 Research Group. (1996). Reclaiming instructional design. Educational Technology, 36 (5), 5-7.

Mitchell S. (1993) Problem based learning: A review of literature on its outcomes and implementation issues. Acad Med 1993;68 (1): 5281.

Nunan, D. (1989). Designing Tasks for the Communicative Classroom, Cambridge University Press.

Prensky, M. (2001). Digital Game-Based Learning. New York: McGraw-Hill.

Savery, J, R. and Duffy, T, M (1995) Problem Based Learning: An instructional model and its constructivist framework, B. Wilson (Ed) Constructivist Learning Environments: Case Studies in Instructional Design, 1995, 135-150

Schroeder, U., Spannagel, C. (2006) Supporting the Active Learning Proces, International Journal on E-Learning. 5 (2), pp. $245-264$. Chesapeake, VA: AACE.

Yacci, M. (2004). Game-Based Learning: Structures and Outcomes. In C. Crawford et al. (Eds. ), Proceedings of Society for Information Technology and Teacher Education International Conference 2004 (pp. 1894-1896). Chesapeake, VA: AACE. 
ISSN 2239-978X

ISSN 2240-0524
Journal of Educational and Social Research MCSER Publishing, Rome-Italy
Vol. 5 No.1 S1 April 2015 